Technical Progress Report

Seventh Quarter

(April 1, 1996 - June 30, 1996)

DOE/PC/94226-.T4

\title{
DEVELOPMENT OF A VIDEO-BASED SLURRY SENSOR
}

FOR ON-LINE ASH ANALYSIS

\author{
Principal Investigators \\ G.T. Adel and G. H. Luttrell \\ Department of Mining and Minerals Engineering \\ Virginia Polytechnic Institute and State University \\ Blacksburg, Virginia 24061
}

Contract Number

DE-FG22-94PC94226

DOE Project Officer

Richard B. Read

United States Department of Energy

Pittsburgh Energy Technology Center

P. O. Box 10940

Pittsburgh, Pennsylvania 15236-0940

July 22,1996

"US/DOE patent clearance is not required prior to the publication of this document."

NIETDIAITION OF THIS DOCUMENT IS UNLRMITED 


\section{DISCLAIMER}

Portions of this document may be illegible in electronic image products. Images are produced from the best available original document. 


\begin{abstract}
Automatic control of fine coal cleaning circuits has traditionally been limited by the lack of sensors for on-line ash analysis. Although several nuclear-based analyzers are available, none have seen widespread acceptance. This is largely due to the fact that nuclear sensors are expensive and tend to be influenced by changes in seam type and pyrite content. Recently, researchers at VPI\&SU have developed an optical sensor for phosphate analysis. The sensor uses image processing technology to analyze video images of phosphate ore. It is currently being used by PCS Phosphate for off-line analysis of dry flotation concentrate. The primary advantages of optical sensors over nuclear sensors are that they are significantly cheaper, are not subject to measurement variations due to changes in high atomic number minerals, are inherently safer and require no special radiation permitting. The purpose of this work is to apply the knowledge gained in the development of an optical phosphate analyzer to the development of an on-line ash analyzer for fine coal slurries.

During the past quarter, an industrially-hardened version of the video-based ash analyzer was designed and constructed. All components are now in place at the Middle Fork plant site awaiting the installation of a sample line from the flotation columns to the analyzer. The sensor now appears ready for long-term, in-plant testing during the final quarter of this project.
\end{abstract}

\title{
DISCLAIMER
}

\begin{abstract}
This report was prepared as an account of work sponsored by an agency of the United States Government. Neither the United States Government nor any agency thereof, nor any of their employees, makes any warranty, express or implied, or assumes any legal liability or responsibility for the accuracy, completeness, or usefulness of any information, apparatus, product, or process disclosed, or represents that its use would not infringe privately owned rights. Reference herein to any specific commercial product, process, or service by trade name, trademark, manufacturer, or otherwise does not necessarily constitute or imply its endorsement, recommendation, or favoring by the United States Government or any agency thereof. The views and opinions of authors expressed herein do not necessarily state or reflect those of the United States Government or any agency thereof.
\end{abstract}




\section{INTRODUCTION}

Automatic control of fine coal cleaning circuits has traditionally been limited by the lack of sensors available for on-line ash analysis. Although a number of nuclear-based slurry analyzers have been tested, none have received widespread acceptance. This is largely due to the fact that nuclear sensors are very expensive for the limited accuracy available. They also tend to be influenced by changes in seam type and pyrite content.

Over the past three years, the principle investigators of this work have developed and installed two optical phosphate analyzers at the PCS Phosphate operation near Aurora, North Carolina. These devices use image processing technology to analyze video images of phosphate flotation concentrates and determine the $\mathrm{P}_{2} \mathrm{O}_{5}$ content and $\mathrm{CaO} / \mathrm{P}_{2} \mathrm{O}_{5}$ ratio. They are currently being used in an off-line configuration on dry samples.

The primary advantages of optical sensors over nuclear sensors are that they are significantly cheaper (i.e., approximately $10 \%$ of the cost), are not subject to measurement variations due to changes in high atomic number minerals, are inherently safer and require no special radiation permitting. Previous experience has also shown that they are more easily understood and accepted by plant operators.

The purpose of this project is to apply the knowledge gained in the development of the optical phosphate analyzer to the development of an on-line sensor for measuring ash content in fine coal slurries. Included in this effort is fundamental research to determine the appropriate light source, image processing algorithms and sample presentation scheme necessary for coal slurry analysis. The following is a summary of work completed during the seventh quarter of this project. 


\section{PROJECT TASKS}

\section{Task 1 - Project Planning}

All project planning activities under Task 1 are now complete. Periodic meetings with personnel at Pittston Coal Company are being held to keep them apprised of progress on the development of the optical ash analyzer.

\section{Task 2 - Laboratory Testing}

All work associated with the development of software and mathematical correlations for video-based ash analysis is now complete. Refinements to the analyzer will continue to be made as new data are acquired during in-plant testing (Task 5).

\section{Task 3 - Bench-Scale Testing}

All work associated with the design and development of a slurry sample presentation system is now complete. Refinements to this system will continue to be made as new information is collected during in-plant testing (Task 5).

\section{Task 4 - Pilot-Scale Testing}

All work associated with the calibration and testing of the video-based ash analyzer has now been completed. The outcome of this task was the development of an analyzer which has a resolution of $0.46 \%$ ash per gray level increment and an accuracy of $\pm 2 \%$ ash, absolute ( $2.5-3.0 \%$ ash, relative). It is expected that the performance measures of the sensor (resolution and accuracy) will be updated as more information is obtained from the in-plant testing work (Task 5). 


\section{Task 5 - In-Plant Testing}

Task 5.1 - Procurement and Fabrication: Most of the hardware and software needed for this task were already purchased in order to carry out the developmental work. The primary additional purchases have included cables for carrying video and electrical signals between the sensor and the control room, and a means of housing the sampling system to allow it to withstand the plant environment over an extended period of time. All components of the industrially-hardened system are now in place and on-site at the Middle Fork preparation plant.

Task 5.2 - Installation and Calibration: Installation of the industrially-hardened video ash analyzer is now underway. A schematic of the proposed system is shown in Figure 1. The basic modifications being made at the plant site are described as follows.

The five operating flotation columns at the Middle Fork preparation plant already have a sampling system which allows samples to be taken from each individual column or any combination of columns for each of the three process streams (feed, tailings and clean coal). The existing tailings sample lines are under modification to provide a continuous flow of tailings slurry from all five columns to the sample presentation system. There is ample room along the plant wall, where the sampling ports currently exist, for the ash analysis system to be installed. Initially the tailings sample presented to the ash analyzer will be a combination of the tailings from all of the columns. This configuration may be changed at a later date to allow for analysis of any particular column. The slurry will be gravity-fed from the sample line to the sample presentation system sump eliminating the need for any intermediate pumping system. 
In addition to the sample line, the Middle Fork plant is installing a dedicated 120volt electrical line to power the sample presentation system. An air line is also being installed to provide a means of pulsing the slurry in the sample presentation tube.

The PC image analysis system will be placed on the top floor of the plant in the operator control room. The sample presentation system will be located on the bottom floor of the plant near the existing sampling ports. These two components of the videobased ash analysis system will be linked by a video cable and a low voltage signal line. The video cable will transmit the live image from the camera to the PC for image analysis and subsequent ash determination. The low voltage signal line will provide signals from the PC to the solenoid valve in the sample presentation tube to allow a fresh sample to be acquired from the sump. Initially, these lines will be temporarily installed. Once a workable configuration has been established, a permanent conduit will be added.

A heavy duty industrial cabinet will be used to house the sample presentation system. It should eliminate any problems which may occur due to the harsh environment in which the sensor will be operating. Once in place, the electrical and air lines will be permanently placed on the cabinet wall to provide power and air for the system. The sample sump will be bottom-fed through the cabinet wall, and a laundering system will collect the overflowing slurry. The sump will be fed at such a rate that mixerless operation will be possible. The overflow material will run into a nearby floor sump. Samples from the system will be collected from the line exiting the sample presentation system. These samples will then be analyzed and compared to the results obtained by the video-based image analyzer, which will allow the calibration to be further improved. 


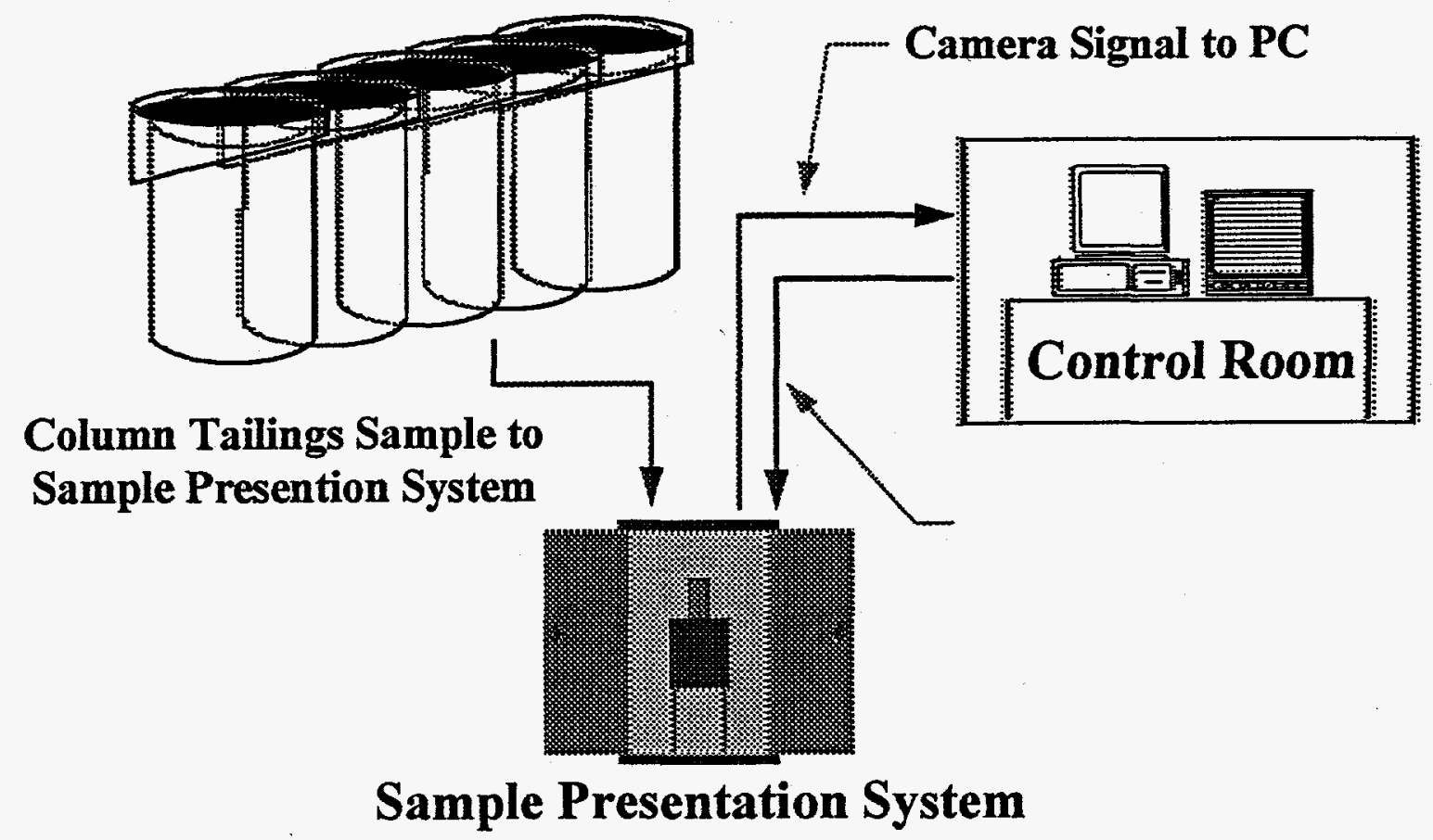

Figure 1. Schematic of the industrially-hardened video-based ash analyzer. 


\section{Task 6-Sample Analysis and Characterization}

The samples being used in this project have been acquired from Pittston's Middle Fork preparation plant. The feed to this plant is dredged from an existing tailings impoundment and treated by a combination of spiral concentrators and column flotation. Flotation tailing samples have generally been found to vary from $65-85 \%$ ash while feed samples range from $38-50 \%$ ash and concentrate samples from $6-7 \%$ ash. As in-plant testing proceeds, numerous samples will continue to be collected and analyzed as required.

\section{SUMMARY STATUS AND FUTURE WORK}

Major accomplishments during the past quarter are listed as follows:

1. All necessary components for installing an industrially-hardened version of the videobased ash analyzer have been purchased and/or fabricated. The components are now on-site and in-place at the Middle Fork preparation plant.

2. All arrangements have been made with plant personnel to provide a continuous stream of slurry to the ash analyzer. This sample stream is currently being installed.

3. Additional arrangements have been made with plant personnel to provide the necessary wiring and other infrastructure for the ash analyzer. All of these details are currently being handled.

As shown in Table 1, the project appears to be nearly on schedule. Tasks 1, 2,3 and 4 are now complete and Task 5 is well underway. In-plant testing of the video-based ash analyzer should be completed during the final quarter with all work elements concluded on time. 
Table 1. Project Schedule

\begin{tabular}{|c|c|}
\hline Task & $\begin{array}{l}\text { Month } \\
24681012141618202224\end{array}$ \\
\hline Task 1 - Project Planning & \multirow[t]{5}{*}{-} \\
\hline Task 2 - Laboratory Testing & \\
\hline Task 3 - Bench-Scale Testing & \\
\hline Task 4 - Pilot-Scale Testing & \\
\hline $\begin{array}{l}\text { Task } 5 \text { - In-Plant Testing } \\
\text { Task 5.1 - Procurement and Fabrication } \\
\text { Task 5.2 - Installation and Calibration } \\
\text { Task 5.3 - Operation/Testing/Refinement }\end{array}$ & \\
\hline Task 6 - Sample Analysis \& Characterization & $\neq$ \\
\hline
\end{tabular}

